\title{
Effects of Intravenous and Intracerebroventricular Theophylline on Hypoxic Ventilatory Depression in Anesthetized Cats
}

\author{
N.K. Yelmen ${ }^{a} \quad$ G. Turgut ${ }^{b} \quad$ G. Şahin ${ }^{a}$ T. Oruça \\ aDepartment of Physiology, Cerrahpaşa Faculty of Medicine, Istanbul University, Cerrahpaşa, Istanbul, and \\ ${ }^{b}$ Department of Physiology, Pamukkale Faculty of Medicine, Pamukkale University, Denizli, Turkey
}

\section{Key Words}

Moderate hypoxia - Hypoxic depression of ventilation .

Theophylline

\begin{abstract}
Objective: The present study was undertaken to investigate the ventilatory response due to sustained isocapnic moderate hypoxia and the possible role of adenosine in hypoxic depression in anesthetized cats. Materials and Methods: Cats anesthetized with pentothal sodium (30 mg kg-1 i.p.) were divided into two groups: treated ( $n=11)$ and control $(n=15)$. Respiratory frequency ( $f)$, tidal volume $\left(\mathrm{V}_{\mathrm{T}}\right)$, minute volume $(\dot{\mathrm{V}} \mathrm{E})$ and systemic arterial blood pressure were recorded during air and $20 \mathrm{~min}$ of breathing hypoxic gas mixture $\left(14 \% \mathrm{O}_{2}-86 \% \mathrm{~N}_{2}\right)$. Isocapnia was maintained by adding fractions of $1 \% \mathrm{CO}_{2}$ to the inspired hypoxic gas mixture. The $\mathrm{PaO}_{2}$ and $\mathrm{PaCO}_{2}$ were determined. Results: On hypoxic gas mixture breathing, $\mathrm{V}_{\mathrm{T}}$ and $\dot{\mathrm{V}}$ v values of the control animals increased significantly, at $5 \mathrm{~min}$ to $50 \pm 6$ and $53 \pm 6 \%$, respectively, above the prehypoxic air phase value $(p<0.001)$. After that, the magnitude of increase in $V_{T}$ and $\dot{V} E$ declined gradually. At 20 min of hypoxia, $\mathrm{V}_{\mathrm{T}}$ and $\dot{\mathrm{V}} \mathrm{E}$ were less than those in prehypoxic air phase $(17 \pm 7,16 \pm 7 \%$, respectively). In cats injected with an adenosine antagonist
\end{abstract}

(theophylline $13.6 \mathrm{mg} \mathrm{kg}^{-1}$ i.v.), $\mathrm{f}, \mathrm{V}_{\mathrm{T}}$ and $\dot{\mathrm{V}} \mathrm{E}$ increased significantly at $5 \mathrm{~min}$ of hypoxia $(\mathrm{p}<0.001)$. At $20 \mathrm{~min}$ of hypoxia, $f, V_{T}$ and $\dot{V} E$ were $8 \pm 2,30 \pm 8$, and $39 \pm 8 \%$, respectively, higher than corresponding values of the prehypoxic stage. In cats injected with theophylline ( $0.5 \mathrm{mg} \mathrm{kg}^{-1}$ ) by cisternal puncture $\mathrm{V}_{\mathrm{T}}$ and $\mathrm{V} E$ increased significantly at $5 \mathrm{~min}$ of hypoxia. At $20 \mathrm{~min}$ of hypoxia, $\mathrm{V}_{\mathrm{T}}$ and $\dot{V} E$ were $27 \pm 7$ and $31 \pm 8 \%$ higher than those in the prehypoxic air phase. Conclusion: The results of this study show that accumulation of adenosine in the brain during hypoxia seems to reduce the response of the central mechanisms to chemoreceptor impulses.

Copyright $@ 2004$ S. Karger AG, Basel

\section{Introduction}

The ventilatory response to isocapnic sustained hypoxia is biphasic $[1,2]$. A rapid increase in ventilation is followed by a decrease in respiratory minute volume [1-3]. The initial rise in ventilation is due to stimulation of the peripheral chemoreceptors. The secondary decrease is thought to be of central origin $[1,2]$ and has been termed 'hypoxic depression' or 'roll-off' [2, 4, 5]. Hypoxic depression of ventilation is absent when the brain stem is kept hyperoxic by artificial perfusion [1]. It is well known that

\begin{tabular}{ll}
\hline KARGER & ( 2004 S. Karger AG, Basel \\
Fax +4161306 1234 & 1011-7571/04/0135-0277\$21.00/0 \\
$\begin{array}{l}\text { E-Mail karger@karger.ch } \\
\text { www.karger.com }\end{array}$ & $\begin{array}{l}\text { Accessible online at: } \\
\text { www.karger.com/mpp }\end{array}$
\end{tabular}

Nermin Karaturan Yelmen

Department of Physiology, Cerrahpaşa Faculy of Medicine Istanbul University

TR-34303 Cerrahpaşa, Istanbul (Turkey)

Tel. +902124143071, Fax +902124143072, E-Mail nermink@istanbul.edu.tr 
peripheral chemoreceptors mediate the hyperventilatory response to hypoxia. In the absence of peripheral chemoreceptor inputs, hypoxia does not produce a hyperventilatory response. It has been clearly shown that hypoxia depresses ventilation in peripherally chemodenervated animals with or without vagotomy due to its central depressant effect [6-8]. Direct evidence of a central depressant effect of hypoxia was also obtained from artificial perfusion studies in which hypoxia was exclusively applied to the brain stem $[9,10]$. In these studies the pons, medulla oblongata and cerebellum of anesthetized cats were perfused artificially with blood in which blood gas tensions varied independently from those in the systemic circulation hence leading to a separation of the central and peripheral effect of $\mathrm{O}_{2}$ tension on ventilation. The studies showed that the central depression of ventilation was caused by decreases in $\mathrm{CO}_{2}$ tension at the central chemosensors during hypoxia induced by increases in cerebral blood flow and Haldane effect [10,11]. Artificial perfusion studies have also shown that the functioning of respiratory neurons in the brain stem is unaltered during moderate central hypoxemia $\left(\mathrm{PaO}_{2} 50 \mathrm{~mm} \mathrm{Hg}\right)$ [9]. On the other hand, hypoxia influences the rate of synthesis or release of neurotransmitters and modulators [12, 13], leading to accumulation of adenosine, dopamine and $\gamma$ aminobutyric acid in the brain $[2,14,15]$. Administration of long-acting analogues of adenosine, either systemically or directly into the third cerebral ventricle, decreases phrenic nerve activity in peripherally chemodenervated air breathing cats while theophylline, a specific antagonist of adenosine, prevents and reverses the decrease of phrenic activity [16] as reported by Javaheri et al. [17]. These studies $[16,17]$ clearly show the important role of adenosine in the central depressant effect of hypoxia in respiration in chemodenervated animals.

Adenosine is thought to be responsible for the depression of ventilation in chemodenervated animals during hypoxia. However, the cause of the secondary decrease of ventilation, which occurs in subjects with intact peripheral chemoreceptors during sustained moderate isocapnic hypoxia, has not been clarified. The neurotransmitters and neuromodulators that accumulate in the brain during hypoxia are thought to be responsible for the secondary decrease, but the particular neurotransmitter is not known. Adenosine, which is present in the brain in low concentration during normoxia and that increases during hypoxia, may also be responsible for this secondary decrease of ventilation in subjects with intact peripheral chemoreceptors during sustained moderate isocapnic hypoxia.
Therefore, in this study, the respiratory effects of theophylline, a central and peripheral adenosine receptor antagonist, on isocapnic moderate hypoxia in anesthetized cats were compared to those in a control group.

\section{Materials and Methods}

The experiments were conducted in cats anesthetized with Pentothal-Na (30 mg kg-1 i.p.). A tracheotomy was done and a cannula connected to an inspiratory-expiratory valve was inserted into the trachea. Catheters were inserted into both femoral arteries for obtaining blood samples and for recording the systemic arterial pressure. The femoral vein was catheterized for administration of doses of anesthetic when necessary.

Fifteen cats were used as a control group. Eleven cats were injected with a specific adenosine antagonist (theophylline $13.6 \mathrm{mg}$ $\mathrm{kg}^{-1}$ i.v.). In order to eliminate its peripheral effects, in 5 cats theophylline $\left(0.51 \mathrm{mg} \mathrm{kg}^{-1}\right)$ was injected into the cerebrospinal fluid (i.c.) by atlanto-occipital puncture over a 1-min period. All experimental animals were allowed to breathe either atmospheric air or $14 \% \mathrm{O}_{2}-\mathrm{N}_{2}$ from the spirometer for $20 \mathrm{~min}$.

Tidal volume $\left(\mathrm{V}_{\mathrm{T}}\right)$, respiratory frequency $(\mathrm{f})$ and arterial blood pressure were recorded while animals were breathing air and a hypoxic gas mixture. $\mathrm{PaO}_{2}$ and $\mathrm{PaCO}_{2}$ were determined. In order to maintain isocapnia, fractions of $1 \% \mathrm{CO}_{2}$ were added to the spirometer. $\mathrm{PaCO}_{2}$ was maintained at the baseline value recorded before the prehypoxic phase. Systemic arterial pressure was recorded using a Statham pressure transducer. $\mathrm{PaO}_{2}$ and $\mathrm{PaCO}_{2}$ were determined using a AVL Gas check analyzer. Respiratory minute volume ( $\dot{\mathrm{V} E})$ was calculated from $V_{T}$ and $f$ values. $V_{T}$ and $f$ were recorded by means of a pneumotachograph and a PT5 volumetric pressure transducer on a Grass 7 polygraph.

Results were statistically analyzed with a repeated-measures ANOVA. For adjustment of multiple comparisons, least significant difference was used ( $p<0.05$ was taken as statistically significant).

\section{Results}

When control animals were allowed to breathe the hypoxic gas mixture, $\mathrm{V}_{\mathrm{T}}$ and $\dot{\mathrm{V}} \mathrm{E}$ increased significantly at 5 min (table 1). After this time, the magnitude of the increase in $\mathrm{V}_{\mathrm{T}}$ diminished gradually. At 10-15 min after the onset of isocapnic hypoxia, $\mathrm{V}_{\mathrm{T}}$ and $\dot{\mathrm{V} E}$ values were not significantly different from the prehypoxic air phase. At 20 min after the onset of isocapnic hypoxia, $\dot{V} E$ was found to be significantly $(\mathrm{p}<0.05)$ lower than that observed during the prehypoxic air phase (table 1).

$\mathrm{PaCO}_{2}$ of the control animals was $34.7 \pm 0.8$ during the prehypoxic air phase and was kept within $\pm 2 \mathrm{~mm} \mathrm{Hg}$ of control while animals were breathing the hypoxic gas mixture (table 1). The mean values of the systemic blood arterial pressure during the air breathing phase and $5 \mathrm{~min}$ after hypoxia were $162.2 \pm 2.5$ and $169.3 \pm 1.9 \mathrm{~mm}$ 
Table 1. Ventilatory and blood gas determinations for control and theophylline-injected (i.v. and i.c.) groups during air and isocapnic hypoxic phases (means $\pm \mathrm{SE}$ )

\begin{tabular}{|c|c|c|c|c|c|c|}
\hline & & $f, \min ^{-1}$ & $\mathrm{~V}_{\mathrm{T}, \mathrm{ml}}$ & $\dot{\mathrm{VE}}, \mathrm{ml}$ & $\mathrm{PaO}_{2}, \mathrm{~mm} \mathrm{Hg}$ & $\mathrm{PaCO}_{2}, \mathrm{~mm} \mathrm{Hg}$ \\
\hline \multirow{5}{*}{$\begin{array}{l}\text { Control } \\
(n=15)\end{array}$} & air & $24.6 \pm 1.5$ & $25.9 \pm 3.8$ & $605.6 \pm 70.2$ & $97.3 \pm 2.1$ & $34.7 \pm 0.8$ \\
\hline & 5-min hypoxia & $25.5 \pm 1.6$ & $36.6 \pm 4.3^{* * *}$ & $895.5 \pm 85.2^{* * *}$ & $66.8 \pm 1.3^{* * *}$ & $33.4 \pm 0.6$ \\
\hline & 10-min hypoxia & $23.9 \pm 1.1$ & $22.4 \pm 2.3$ & $509.2 \pm 58.7$ & $68.6 \pm 1.0^{* * *}$ & $32.5 \pm 1.0$ \\
\hline & 15-min hypoxia & $24.7 \pm 1.1$ & $19.1 \pm 3.2$ & $458.2 \pm 7.2$ & $65.5 \pm 2.0^{* * *}$ & $32.4 \pm 0.8$ \\
\hline & 20-min hypoxia & $23.9 \pm 1.1$ & $22.2 \pm 3.3$ & $465.2 \pm 52.6^{*}$ & $63.8 \pm 4.5^{* * *}$ & $32.0 \pm 1$ \\
\hline \multirow{5}{*}{$\begin{array}{l}\text { i.v. theophylline } \\
(\mathrm{n}=11)\end{array}$} & air & $25.9 \pm 1.5$ & $39.4 \pm 3.0$ & $995.9 \pm 74.8$ & $99.3 \pm 2.5$ & $32.3 \pm 0.5$ \\
\hline & 5-min hypoxia & $27.7 \pm 1.5^{* *}$ & $49.8 \pm 3.1^{* * *}$ & $1,374.1 \pm 107.9^{* * *}$ & $65.9 \pm 1.1^{* * *}$ & $32.3 \pm 0.5$ \\
\hline & 10-min hypoxia & $28.1 \pm 1.6^{* *}$ & $48.5 \pm 3.7^{* *}$ & $1,358.4 \pm 125.9^{* *}$ & $66 \pm 1.1 * * *$ & $33.5 \pm 1.0$ \\
\hline & 15-min hypoxia & $28.7 \pm 1.8^{*}$ & $48.4 \pm 4.4^{*}$ & $1,359.4 \pm 128^{* *}$ & $65.1 \pm 2.0^{* * *}$ & $33.2 \pm 1.2$ \\
\hline & 20-min hypoxia & $29 \pm 1.7 * *$ & $49.8 \pm 3.5^{* *}$ & $1,418 \pm 110.3^{* * *}$ & $66 \pm 1.2^{* * *}$ & $33.3 \pm 1.7$ \\
\hline \multirow{5}{*}{$\begin{array}{l}\text { i.c. theophylline } \\
(\mathrm{n}=5)\end{array}$} & air & $21.6 \pm 1.2$ & $32.7 \pm 1.0$ & $705.2 \pm 44.9$ & $99.4 \pm 3.1$ & $39.2 \pm 0.9$ \\
\hline & 5-min hypoxia & $22.2 \pm 1.3$ & $40.6 \pm 1.2^{* *}$ & $897.3 \pm 45.3^{* *}$ & $68.7 \pm 1^{* * *}$ & $36.7 \pm 0.6$ \\
\hline & 10-min hypoxia & $22 \pm 1.2$ & $41.4 \pm 0.6^{* *}$ & $909.2 \pm 46.9^{* *}$ & $65.6 \pm 1^{* * *}$ & $36.5 \pm 0.9$ \\
\hline & 15-min hypoxia & $22.4 \pm 0.9$ & $40.6 \pm 1.1^{*}$ & $912.2 \pm 51.7 *$ & $65.6 \pm 0.8^{* * *}$ & $37.6 \pm 0.7$ \\
\hline & 20-min hypoxia & $22.2 \pm 440.5$ & $41.1 \pm 1.1^{* *}$ & $911.8 \pm 41.6^{*}$ & $66.8 \pm 1 * * *$ & $38.1 \pm 1.0$ \\
\hline
\end{tabular}

$\mathrm{f}=$ Respiratory frequency; $\mathrm{V}_{\mathrm{T}}=$ tidal volume; $\dot{\mathrm{V} E}=$ ventilatory minute volume. Asterisks indicate statistical significance when compared with the prehypoxic air phase: ${ }^{*} \mathrm{p}<0.05,{ }^{* *} \mathrm{p}<0.01,{ }^{* * *} \mathrm{p}<0.001$.

Table 2. Mean arterial blood pressure determination for control, i.v. theophylline and i.c. theophylline groups during air and isocapnic hypoxic phases (means $\pm \mathrm{SE}$ )

\begin{tabular}{lccccc}
\hline \multicolumn{5}{c}{ Mean arterial blood pressure, $\mathrm{mm} \mathrm{Hg}$} \\
\cline { 2 - 6 } & air breathing & 5-min hypoxia & 10-min hypoxia & 15-min hypoxia & 20-min hypoxia \\
\hline Control $(\mathrm{n}=15)$ & $162.2 \pm 2.5$ & $169.3 \pm 1.9^{* * *}$ & $161.8 \pm 8.8$ & $162.1 \pm 8.3$ & $162 \pm 7.5$ \\
i.v. theophylline $(\mathrm{n}=11)$ & $127.4 \pm 5.7$ & $128.6 \pm 5.4$ & $126.2 \pm 6.2$ & $120 \pm 7.1$ & $120 \pm 7.1$ \\
i.c. theophylline $(\mathrm{n}=5)$ & $130 \pm 9.3$ & $131 \pm 10.2$ & $129 \pm 10.9$ & $126.5 \pm 10.9$ & $124 \pm 10.4^{*}$
\end{tabular}

Asterisks indicate statistical significance when compared with the prehypoxic air phase: $* p<0.05$, $* * * \mathrm{p}<0.001$.

Hg. Both paired t test and repeated-measures ANOVA showed that the difference was statistically significant $(p<0.001)$. At 10, 15 and 20 min of hypoxia, the systemic arterial pressure values were not different from those observed during the prehypoxic air phase (table 2).

In cats with i.v. injections of theophylline, $\mathrm{f}, \mathrm{V}_{\mathrm{T}}$ and $\dot{V} E$ increased significantly $(p<0.01, p<0.001, p<0.001)$ at $5 \mathrm{~min}$ of hypoxia. No decrease in the magnitude of the ventilatory response was observed during the 20-min period of hypoxic gas mixture breathing. At $20 \mathrm{~min}$ after the onset of hypoxia, $f, V_{T}$ and $\dot{V} E$ values were significant- ly $(\mathrm{p}<0.01, \mathrm{p}<0.01, \mathrm{p}<0.001)$ greater than observed during the prehypoxic air phase (table 1). In cats injected with theophylline (i.c.), $\mathrm{V}_{\mathrm{T}}$ and $\dot{\mathrm{V}} \mathrm{E}$ increased significantly $(\mathrm{p}<0.01, \mathrm{p}<0.01)$ at $5 \mathrm{~min}$ of hypoxia. After this time, no decline in the magnitude of the response occurred during isocapnic hypoxia (table 1). In both theophylline-injected groups (i.v. and i.c.) no significant increase was observed in systemic arterial pressure during isocapnic hypoxia (table 2). 


\section{Discussion}

Our results show that sustained (20-min) isocapnic moderate hypoxia causes an initial increase in ventilation followed by a decrease in respiratory minute volume. The initial increase in ventilation is brought about by the stimulation of peripheral chemoreceptors. Previous studies have demonstrated that the peripheral chemoreceptors are stimulated in acute hypoxia and in sustained hypoxia $[4,18]$. The subsequent decline in ventilation ( $\dot{\mathrm{V} E})$ that we observed was due to a decrease in $\mathrm{V}_{\mathrm{T}}$. No change was observed in respiratory frequency. The peripheral chemoreceptors have been shown to be active during ventilatory decline [4]. Vizek et al. [4] observed no decrement in carotid sinus nerve activity during ventilatory depression in sustained hypoxia. However, they observed a decrease in phrenic nerve activity [4]. These findings indicate that central mechanisms are responsible for the subsequent decrease of ventilation in sustained hypoxia. The central depressant effect of hypoxia on ventilation and particularly on $\mathrm{V}_{\mathrm{T}}$ has long been established in chemodenervated and chemodenervated vagotomized animals $[6,8,11]$. The decrease in ventilation of chemodenervated animals during hypoxia was attributed to an increase in cerebral blood flow and the consequent decrease in cerebrospinal fluid $\mathrm{PCO}_{2}$ [11] and to the release of inhibitory neurotransmitters $[12,13,16]$. However, studies by Javaheri et al. [17] on chemodenervated-vagotomized animals have shown that hypoxic ventilatory depression occurs both in the face of a rise or a fall in ventral medullary extracellular fluid $\mathrm{PCO}_{2}$ and $\mathrm{H}^{+}$and is prevented by aminophylline.

In our present study $V_{T}$ and $V_{E}$ values of the theophylline-treated groups were higher than those of the control group during the air phase. This observation supports the findings of Eldridge et al. [19].The results of these investigators showed that theophylline increases the respiratory drive by means of central neural mechanisms. Adenosine, which is present in the brain in low concentration, is known to inhibit the spontaneous neural activity in various parts of the brain. Theophylline, on the other hand, blocks the effects of adenosine by binding to the adenosine receptors. It is for this reason that $\mathrm{V}_{\mathrm{T}}$ and $\mathrm{V}_{\mathrm{E}}$ values of the theophylline-treated groups can be expected to be higher than those of the untreated group. When theophylline-treated groups were exposed to sustained moderate isocapnic hypoxia, respiration $\left(\mathrm{V}_{\mathrm{T}}, \dot{\mathrm{V}} \mathrm{E}\right)$ increased significantly in the first 5 min and remained at an increased level during the entire 20-min phase of hypoxic gas breathing. Secondary depression of ventilation was not observed in theophylline-treated groups. In other words, the subse- quent decrease of ventilation that we observed in cats with intact peripheral chemoreceptors and vagi was absent in the i.v. and i.c. theophylline (a specific adenosine antagonist) groups. This finding indicates that adenosine, which accumulates in the brain during hypoxia, inhibits the central mechanisms and prevents their response to peripheral chemoreceptor impulses.

In the present study, systemic arterial pressure of the control cats was found to increase significantly at $5 \mathrm{~min}$ of hypoxia. This increase is due to peripheral chemoreceptor impulses impinging on the vasomotor area. The subsequent decrease in systemic arterial pressure observed after this time may be attributed to accumulation of neurochemical substances that inhibit pressor activity. It may also be due to peripheral effects of hypoxia on the cardiovascular system.

Arterial blood pressure was lower in theophylline groups (i.v. and i.c.). In the i.v. theophylline group this may be due to the systemic vasodilator effect of theophylline [20]. However, blood pressure was also low when theophylline was given i.c., therefore, we suggest a central effect of theophylline on vagal and vasomotor centers in the brain stem. Furthermore, the possibility of adenosine as a mediator cannot be excluded. There is experimental evidence that selective activation of $\mathrm{A}(1)$ adenosine receptors in the subpostremal nucleus tractus solitarii increases mean arterial pressure and causes an increase in preganglionic adrenal sympathetic activity [21]. The low blood pressure in our i.c. theophylline (adenosine antagonist) group may be due to inactivation of $\mathrm{A}(1)$ adenosine receptors in the nucleus tractus solitarii.

\section{Conclusion}

The results of this study show that accumulation of adenosine in the brain during sustained isocapnic moderate hypoxia seems to reduce the response of the central respiratory control mechanisms to chemoreceptor impulses and to cause the subsequent decrease of ventilation. Adenosine antagonist (theophylline) restores the response of central mechanisms to chemoreceptor impulses and prevents the secondary decline of ventilation. 


\section{References}

1 Beckenbosh A, De Gioede J: Effects of brain hypoxia on ventilation. Eur Respir J 1988;1 184-190.

2 Wenging L, Lobchuk D, Anthonisen NR: Ventilatory response to $\mathrm{CO}_{2}$ and hypoxia after sustained hypoxia in awake cats. J Appl Physiol 1994; 76:2262-2266.

3 Wenging L, Giesbrech GG, Anthonisen NR: Ventilatory response to moderate hypoxia in awake chemodenervated cats. J Appl Physiol 1993;74:805-810

4 Vizek M, Pickett KC, Weil VJ: Biphasic ventilatory response of adult cats to sustained hypoxia has central origin. J Appl Physiol 1987;63: 1658-1664.

5 Neubauer JA, Melton JE, Edelman NH: Modulation of respiration during brain hypoxia. $\mathrm{J}$ Appl Physiol 1990;68:441-451.

6 Miller MJ, Tenney SM: Hypoxia-induced tachypnea in carotid deafferented cats. Respir Physiol 1975;23:31-39.

7 Oruç T: The activation of central and peripheral respiratory control mechanisms in hyperoxia and hypoxia. Bull Eur Physiopathol Respir 1982;18:113.

8 Oruç T, Terzioğlu M, Şahin G, Dursun S: Response of the central respiratory control mechanisms to hyperoxia and hypoxia. Bull Eur Physiopathol Respir 1982;18:439-447.
9 van Beek JH, Beckenbosh A, De Goede J, Oliever CN: Effects of brainstem hypoxaemia on the regulation of breathing. Respir Physiol 1984;57:171-189.

10 van Beek JH, Beckenbosh A, Oliever CN, Quanger PhH: Depression of ventilation during brainstem hypoxia in anesthetized cats. Bull Eur Physiopathol Respir 1982;18:139144.

11 Oliever CN, Beckenbosch A, Beek van JH, De Coede J, Quanjer Ph H: Hypoxia, cerebrospinal fluid $\mathrm{PCO}_{2}$ and central depression of ventilation. Bull Eur Physiopathol Respir 1982;18: 165-172.

12 Soto-Arape I, Burton MD, Kazemi H: Central amino acid neurotransmitters and the hypoxic ventilatory response. Am J Respir Crit Care Med 1995;151:1113-1120.

13 Richter DW, Schmidt-Garcon P, Pierrefiche O, Bischoft AM, Lalley PM: Brainstem amino acid neurotransmitters and hypoxic ventilatory response. J Physiol 1999;514:567-578.

14 Melton JE, Neubauer JA, Edelman NH: GABA antagonism reverses hypoxic respiratory depression in the cat. J Appl Physiol 1990;69: 1296-1301.
15 Güner I, Yelmen N, Sahin G, Oruc T: The effect of intracerebroventricular dopamine administration on the respiratory response to hypoxia. Tohoku J Exp Med 2002;196:219_ 230.

16 Eldridge FL, Milhorn DE, Kiley JP: Antagonism by theophylline of respiratory inhibition induced by adenosine. J Appl Physiol 1985;59: 1428-1433.

17 Javaheri S, Teppema LJ, Evers JA: Effects of aminophylline on hypoxemia induced ventilatory depression in the cat. J Appl Physiol 1988; 64:1837-1843.

18 Şahin G, Terzioğlu M: The influence of chronic hypoxia on erythrocytic 2,3-diphosphoglycerate and the sensitivity of peripheral chemoreceptors of rabbits. Cerrahpaşa Med Rev 1985; 4:46-56.

19 Eldridge FL, Millhorn DE, Waldrop TG, Kiley JP: Mechanism of respiratory effects of methylxanthines. Respir Physiol 1983;53:239-261.

20 Lincoln TM, Cornwell TL, Taylor A: c-GMPdependent protein kinase mediates the reduction of $\mathrm{Ca}^{2+}$ by cAMP in vascular smooth muscle cells. Am J Physiol 1990;259:399-407.

21 Scislo TJ, O'Leary DS: Mechanisms mediating regional sympathoactivatory responses to stimulation of NTS A(1) adenosine receptors. Am J Physiol Heart Circ Physiol 2002;283:H1588H1599. 